\title{
General Psychiatry The cost of obsessive-compulsive disorder (OCD) in China: a multi-center cross-sectional survey based on hospitals
}

Weili Yang (1) , ${ }^{1,2}$ Zhen Tang, ${ }^{3}$ Xijin Wang, ${ }^{4}$ Xiancang Ma, ${ }^{5}$ Yuqi Cheng, ${ }^{6}$ Bin Wang, ${ }^{7}$ Ping Sun, ${ }^{8}$ Wenxin Tang, ${ }^{9}$ Jia Luo, ${ }^{10}$ Changhong Wang, ${ }^{2}$ Ping Li ${ }^{11}$ Guiyun $\mathrm{Xu},{ }^{12}$ Jun Yan, ${ }^{13}$ Vlasios Brakoulias, ${ }^{14}$ Zhen Wang (D) ${ }^{1}$

To cite: Yang W, Tang Z, Wang X, et al. The cost of obsessivecompulsive disorder (OCD) in China: a multi-center crosssectional survey based on hospitals. General Psychiatry 2021;34:e100632. doi:10.1136/ gpsych-2021-100632

Received 01 August 2021 Accepted 26 October 2021

Check for updates

(c) Author(s) (or their employer(s)) 2021. Re-use permitted under CC BY-NC. No commercial re-use. See rights and permissions. Published by BMJ.

For numbered affiliations see end of article.

Correspondence to

Dr Zhen Wang;

wangzhen@smhc.org.cn

\section{ABSTRACT}

Background Obsessive-compulsive disorder (OCD) is considered a very debilitating disorder with severe loss of quality of life and income.

Aims This study estimates the quality of life and economic consequences of OCD in China.

Methods The research team interviewed 639 patients with OCD in 13 hospitals in 12 cities in China. The direct method was used to get the direct cost of OCD. Indirect costs associated with OCD were estimated using the human capital approach. Linear regression analysis was conducted for quality of life and generalised linear model analysis was conducted for total cost. Sensitivity analysis was used to analyse the uncertainty of total cost.

Results The mean quality of life score for OCD was 52.78 (20.46). The annual total cost of OCD per capita was 24503.78 (95\% Cl: 22621.53 to 26386.03$)$ renminbi (RMB) (US\$3465.88 (95\% Cl: US\$3199.65 to US\$3732.11)). The annual cost of OCD in China was estimated to be 37.74 billion ( $95 \% \mathrm{Cl}: 34.95$ billion to 40.53 billion) RMB (equal to US $\$ 5.34$ billion $(95 \% \mathrm{Cl}$ : US $\$ 4.94$ billion to US\$5.73 billion)). Sensitivity analysis showed that the total annual cost of OCD in China was between 23.15 billion RMB (US\$3.27 billion) and 370.00 billion RMB (US $\$ 52.33$ billion). Worse social function status, more psychiatric symptoms and higher Yale Brown Obsessive-Compulsive Scale (Y-BOCS) score were associated with worse quality of life. The numbers of clinic visits and hospitalisations, socioeconomic status, education, Y-BOCS scores and age were found to be significantly associated with total cost.

Conclusions OCD is associated with low quality of life and high costs in China. The findings call for concerted efforts to improve services for patients with OCD. Improvements may include early detection and diagnosis, the provision of evidence-based treatments and relapse prevention strategies.

\section{INTRODUCTION}

Obsessive-compulsive disorder (OCD) is a debilitating disease with recurrent intrusive obsessions (thoughts, images and urges) and/ or compulsive behaviours. The prevalence of OCD in China is $1.63 \% .^{1}$ OCD usually begins in adolescence or young adulthood; if the symptoms are severe and untreated, OCD can seriously impact on a person's ability to work, study and perform their activities of daily living. ${ }^{23}$ The World Health Organization (WHO) identified OCD as one of the 20 most burdensome diseases for people aged $15-44$ years old. ${ }^{4}$

OCD can come with a huge economic burden to individuals, families and society, but evidence is required to better understand the full impact. According to a US study by DuPont et al in 1990, the total cost of OCD was US\$8.4 billion, accounting for $5.7 \%$ of the cost of treating mental disorders. ${ }^{5}$ The total healthcare expenditure for pure OCD is equivalent to depression in the first 2 years of the initial diagnosis. ${ }^{3}$ Compared with other mental illnesses, the hospitalisation rate for $\mathrm{OCD}$ is lower, and $25 \%$ of patients with $\mathrm{OCD}$ have been hospitalised at some stage of their lives. ${ }^{6}$ The economic losses caused by OCD are more likely to be attributable to unemployment, lost work and reduced productivity. Swedish national survey data show that $11 \%$ of patients with OCD have been unemployed for a long time $(\geq 180$ days per year), Asian patients with OCD have been unemployed for an average of 25.4 days in 1 year. $^{78}$ The economic burden of OCD related to suicide in the USA is estimated to have reached US\$255 million (including comorbidities), accounting for $3 \%$ of the total OCD burden. ${ }^{9}$ There is a need for similar studies to be replicated outside the USA.

The purpose of our article was to assess the quality of life and economic cost of OCD in China. The study is a first attempt to estimate the economic impact of OCD in China using multiple centres. 


\section{METHODS}

\section{Data and study design}

This was a multicentre, hospital-based, cross-sectional study that was conducted from January 2019 to December 2019. This study aimed to estimate the economic burden of OCD, including the patient and their household spending as a result of the disorder. Twelve cities, which are Harbin, Qiqihar, Beijing, Xi'an, Xinxiang, Jinan, Qingdao, Hangzhou, Suzhou, Shanghai, Guangzhou, Kunming, and 13 hospitals were selected as study sites, covering both urban and rural regions in China. These cities are located in various geographical regions of China, covering all levels of China's economy. The hospitals selected to participate in this study were either the largest or the only psychiatric hospital or general hospital in each city, being in charge of the medical service for the majority of the local residents. The sample sources of patients with OCD were distributed in different geographical regions of China and could better cover various burdens of OCD in China.

The inclusion criteria were that patients had a primary diagnosis of OCD with Diagnostic and Statistical Manual of Mental Disorders, fifth edition (DSM-5) ${ }^{10}{ }^{11}$ and aged between 16 and 65 years. Participants were excluded if they had psychotic disorders such as schizophrenia, substance abuse, an inability to understand the questionnaire and patients or their guardians (if any) disagreed to participate.

\section{Healthcare utilisation and burden measures}

The cost of disease was defined as the value of resources spent owing to the disease. The cost of disease includes two parts: direct costs and indirect costs. Direct costs include direct medical costs and direct non-medical costs. Direct medical costs refer to the value of services used to treat diseases. Direct non-medical costs include nonmedical services incurred owing to medical treatment and hospitalisation. Indirect costs are lost productivity owing to illness or death. The sum of the direct and indirect costs of OCD reflects the total economic burden of the disease on society.

There are, currently, two methods of using different types of data sources to estimate the cost of disease: a top-down method and a bottom-up method. The topdown approach uses national survey data identified by disease codes (such as DSM-5) to summarise the total cost of disease in the country. The bottom-up approach is to use the recorded cost of the samples of diagnosed patients. Based on the patient cost of these samples and the prevalence of the disease, the total national cost of the disease can be predicted. The top-down approach is usually representative across the country, but it requires a lot of detailed data from national surveys, which is both time-consuming and costly. In contrast, the bottom-up approach is more accurate for each patient's cost but less accurate for the estimated national cost. Owing to the limited resources available in this study, a bottom-up costing approach was adopted in the estimation of costs associated with OCD.
Each patient was interviewed in a standardised manner face-to-face by a trained investigator according to the survey manual. The patients' self-reports were recorded on the questionnaire. The participants recruited into the trial $(n=639)$ completed an Inventory on the Financial Burden of Obsessive-Compulsive Disorder (IFBOCD) as part of a comprehensive assessment and consented to the study accessing their medical records. Information collected included: the demographic characteristics of the patients and the severity of the OCD as assessed by the Yale Brown Obsessive-Compulsive Scale (Y-BOCS). ${ }^{12}$ The scale is divided into two subscales that separately measure obsessions and compulsions. For each subscale, five aspects of obsessive and compulsive pathology are each rated on a scale ranging from 0 (no symptoms) to 4 (extreme symptoms). Scores above 30 corresponded with severe symptoms, scores between 25 and 30 corresponded with moderate-severe symptoms, scores between 14 and 24 corresponded with moderate symptoms, scores between 5 and 13 corresponded with mild symptoms and scores below 5 were linked with slight or less illness. The quality of life of the OCD was assessed by the 12-Item Short-Form Health Survey Questionnaire (SF-12). ${ }^{13}$ Patients with OCD have more and regular outpatient visits, so outpatient information within 3 months was used to estimate the 1-year outpatient data. IFBOCD included the patients' outpatient information within 3 months, visits outside the clinic within the last 3 months, hospitalisation information of patients within 1 year, patients' work loss and productivity loss within 1 year, patients' family loss and productivity loss caused by patients' OCD within 1 year, other medical costs for patients and families owing to OCD within 1 year, and other costs for patients and families owing to OCD within 1 year, such as the costs incurred by patients owing to obsessive thinking and/or compulsive behaviour destroying items to relieve symptoms.

\section{Direct costs}

There are three kinds of medical insurance systems in China, namely: urban basic medical insurance, basic medical insurance for urban residents and the new rural cooperative medical care, all of which could provide a co-payment for inpatient and some outpatient services, but not for home help. ${ }^{14}$ Patients themselves pay for transportation, room and board, home care and nutrition. Information regarding medical insurance for each patient was recorded. When calculating the mean direct medical costs, medical insurance reimbursement was not considered. At the same time, we also considered the mean family payment after medical insurance reimbursement. The annual direct costs included the diagnosis and treatment of OCD and its complications, for example, additional costs owing to unreasonable suspicion of illness. The direct medical costs of the illness were grouped according to registration costs, drug costs, inspection costs (including image examination and laboratory examination), inpatient costs, treatment 


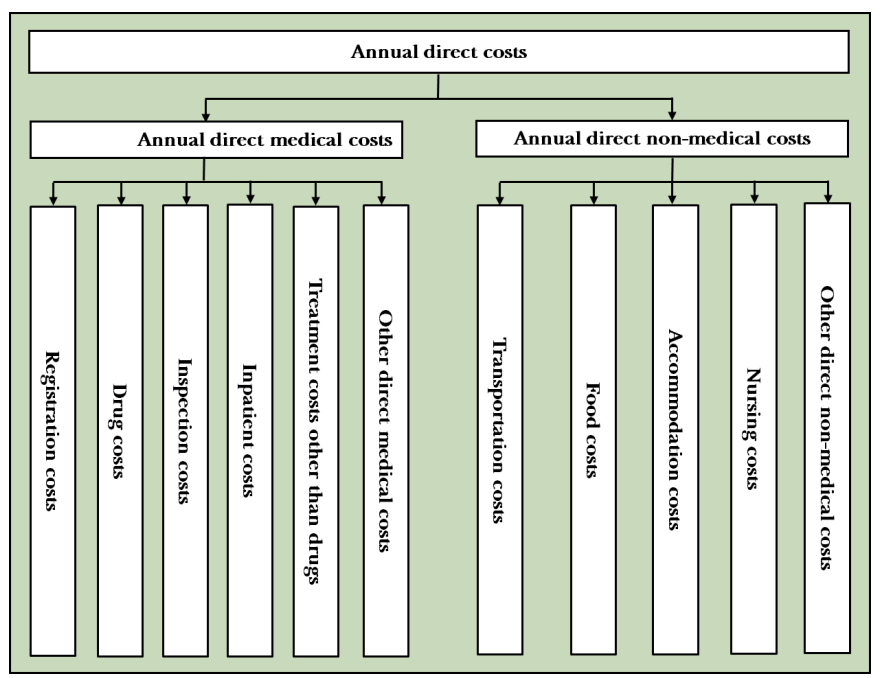

Figure 1 Composition of annual direct costs. OCD, obsessive-compulsive disorder.

costs (psychotherapy, physical therapy and other treatments other than drugs) and other direct medical costs (including the medical costs of complications). The direct non-medical costs of the illness were divided into transportation costs, food costs, accommodation costs, nursing costs and other direct non-medical costs (see figure 1).

\section{Indirect costs}

Indirect costs included time lost by patients and their families because of OCD. Indirect costs were evaluated using the human capital approach. The days lost were multiplied by the average income of the patient's place of residence to obtain the loss of time for the patient indirectly. Similarly, the loss of time of the family (or friends) was also estimated. The annual indirect costs=patients' time loss +their families' time loss +other indirect costs for OCD-related events= (patients' loss days+their families' loss days) $\times$ the average income of their place of residence +other indirect costs for OCD-related events. We also calculated the indirect cost loss reported by the family.

\section{National cost projections}

A prevalence-based cost-of-illness approach was used to estimate the total economic burden of OCD. (1) We first estimated the number of individuals with OCD in China by multiplying the prevalence of OCD by the population aged 16-65 years. (2) The average annual cost of OCD per capita in China was obtained by adding direct medical costs, direct non-medical costs and indirect costs, with weighting by region, gender and age. (3) The total economic burden of patients with OCD in China was obtained, with the average annual cost per patient with OCD from our results multiplied by the number of patients with OCD and multiplied by the rate of consultations for OCD.

\section{Statistical analyses}

Cost data are usually positively skewed, as was the case for the data obtained in this study. ${ }^{15}{ }^{16}$ However, the median cost is zero for highly skewed data. Thus, the statistical description provided the mean values and ranges. The analysis of cost uses a generalised linear model with gamma link function. The quality of life score is normally distributed and described using the mean values and standard deviation (SD). Linear regression analysis was conducted for quality of life. The regression models were calculated with a stepwise forward method. We performed a sensitivity analysis on the estimated total cost. Statistical analyses were performed using SPSS V22.0. A p value less than 0.05 was considered statistically significant. The per capita income of each city comes from the National Bureau of Statistics. The division of regions was based on the economic level, and the gender and age of each region came from the data of the sixth census. The renminbi (RMB) is the national currency of the People's Republic of China and the exchange rate was US $\$ 1=7.07$ RMB in 2020.

\section{RESULTS}

\section{Characteristics of patients with $\mathrm{OCD}$}

There were 639 participants (359 men; 280 women) from 13 hospitals in China's four economic-level regions (see figure 2). The mean age was 30.85 (11.61) years with $85.8 \%(n=527)$ within the age range of $16-44$ years. More than half $(n=329,51.6 \%)$ of the patients were residing in urban locations. Secondary education had been completed in $44.2 \% \quad(\mathrm{n}=281)$ and tertiary education was completed in $57.0 \%(\mathrm{n}=337)$. More than half $(\mathrm{n}=331,51.9 \%)$ were employed. The sample ratios of the four economic levels did not vary significantly. Only $8.6 \%(n=53)$ of the participants reported that the average annual household income was $\leq 30000 \mathrm{RMB}$, while the majority of the participants reported 30 000-80 000 RMB and $80000-150000 \mathrm{RMB}$, accounting for $29.8 \%$ and $33.0 \%$, respectively. The mean duration of OCD was 8.35 years. Almost two-thirds $(n=408,65.4 \%)$ of the patients did not have psychiatric comorbidity. The mean Y-BOCS score was 19.65 (7.61). The social function status of the sample was predominantly in the mild and moderate categories, accounting for $23.7 \% \quad(n=149)$ and $45.6 \%$ $(n=287)$, respectively. The detailed characteristics of the participants are given in table 1 .

\section{The quality of life of patients with $O C D$}

The internal consistency and reliability of the 12-Item Short-Form Health Survey Questionnaire (SF-12) was satisfactory, with a Cronbach's $\alpha$ of 0.849. After standardised scoring, the quality of life score for OCD was 52.78 (20.46). The most affected quality of life for patients with OCD was the Role emotional dimension, with a score of 31.21 (39.44). Physical health and Bodily pain dimensions were least affected, with scores of 77.59 (26.01) and 74.29 (28.12), respectively. Physical Component Summary 


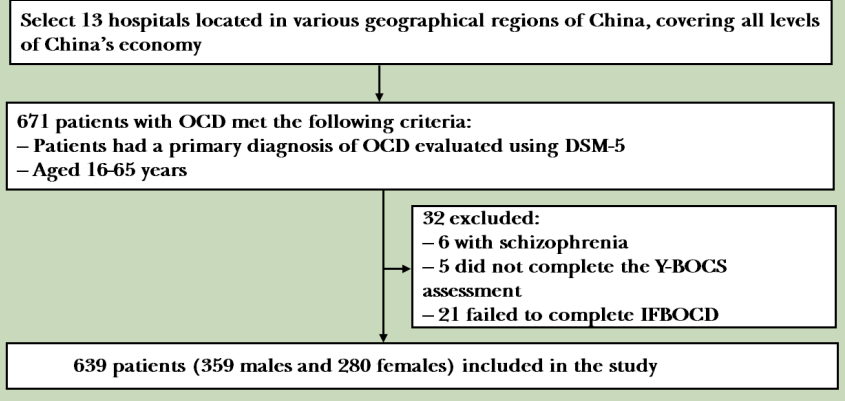

Figure 2 Flowchart of the sample recruitment. DSM-5, Diagnostic and Statistical Manual of Mental Disorders, fifth edition; IFBOCD, Inventory on the Financial Burden of Obsessive-Compulsive Disorder; OCD, obsessivecompulsive disorder; Y-BOCS, Yale Brown ObsessiveCompulsive Scale.

score of OCD was higher than that of Mental Component Summary, the difference is a score of 12.30 (20.56). The scores of other dimensions are shown in table 2.

\section{The costs for patients with OCD}

The annual number of outpatient visits for patients with OCD was 9.96 (95\% CI: 9.31 to 10.61) times. Most patients with OCD $(n=501,78.4 \%)$ were not hospitalised within 1 year. Among the inpatients, the annual average number of hospitalisations was 1.18 (95\% CI: 1.10 to 1.26 ) times, and the average number of hospitalisation days was 32.59 (95\% CI: 27.17 to 38.01$)$ days.

\section{Direct costs}

The direct costs per capita were 13490.27 (95\% CI: 12 324.89 to 14655.65 ) RMB (equal to US\$1908.10 (95\% CI: US\$1743.27 to US\$2072.93)), which accounted for $55.05 \%$ of the total costs of the disease. The average direct costs paid by the family accounted for $41.3 \%$. Among the direct costs of patients with OCD, direct medical costs per capita were 10130.52 (95\% CI: 9241.47 to 11 019.58) RMB (equal to US\$1432.89 (95\% CI: US\$1307.14 to US\$1558.64)), accounting for $75.10 \%$ of the direct costs per capita, and direct non-medical costs per capita were 3359.75 (95\% CI: 2858.94 to 3860.55 ) RMB (equal to US\$475.21 (95\% CI: US\$404.38 to US\$546.05)), accounting for $24.90 \%$. Drug costs and inpatient costs accounted for the highest proportions of direct medical costs for OCD, which were $39.51 \%$ and $33.50 \%$, respectively. Transportation costs accounted for the most direct non-medical costs, which was $56.49 \%$. The nursing costs for OCD were relatively low in comparison, $151.13(95 \%$ CI: 8.15 to 294.11) RMB per person (see table 3).

\section{Indirect costs}

The indirect costs per capita were 11013.51 (95\% CI: 9852.41 to 12174.61 ) RMB (equal to US\$1557.78 (95\% CI: US\$1393.55 to US\$1722.01)), which accounted for $44.95 \%$ of the total costs of the disease. The average indirect costs paid by family accounted for $57.79 \%$. Among the indirect costs of OCD, the patient labour loss days per capita were 80.55 (95\%
Table 1 The demographic and clinical characteristics of patients with OCD $(\mathrm{n}=639)$

\begin{tabular}{|c|c|c|}
\hline Characteristics & $\mathbf{N}(\%)$ & Mean (SD) \\
\hline \multicolumn{3}{|l|}{ Gender } \\
\hline Male & $359(56.2)$ & \\
\hline Female & $280(43.8)$ & \\
\hline Age (years) $(n=614)$ & & $30.85(11.61)$ \\
\hline $16-29$ & $325(52.9)$ & \\
\hline $30-44$ & $202(32.9)$ & \\
\hline$\geq 45$ & $87(14.2)$ & \\
\hline \multicolumn{3}{|l|}{ Resident location $(n=638)$} \\
\hline Rural & $309(48.4)$ & \\
\hline Urban & $329(51.6)$ & \\
\hline \multicolumn{3}{|l|}{ Education $(n=636)$} \\
\hline Primary education & $18(2.8)$ & \\
\hline Secondary education & $281(44.2)$ & \\
\hline Tertiary education & $337(57.0)$ & \\
\hline \multicolumn{3}{|l|}{ Working status $(n=638)$} \\
\hline Student & $185(29.0)$ & \\
\hline Employed & $331(51.9)$ & \\
\hline Retired & $24(3.8)$ & \\
\hline $\begin{array}{l}\text { Unemployed or out of } \\
\text { school }\end{array}$ & $98(15.4)$ & \\
\hline
\end{tabular}

Economic level of residence $(n=632)$

\begin{tabular}{|c|c|c|}
\hline Level 1 & $111(17.6)$ & \\
\hline Level 2 & $155(24.5)$ & \\
\hline Level 3 & $190(30.1)$ & \\
\hline Level 4 & $176(27.8)$ & \\
\hline \multicolumn{3}{|c|}{ Annual household income (RMB) $(n=618)$} \\
\hline$\leq 30000$ & $53(8.6)$ & \\
\hline $30000 \sim 80000$ & $184(29.8)$ & \\
\hline $80000 \sim 150000$ & $204(33.0)$ & \\
\hline$>150000$ & $177(28.6)$ & \\
\hline \multicolumn{2}{|c|}{ Duration of OCD (years) $(n=614)$} & $8.35(7.77)$ \\
\hline $0-5$ years & $266(43.3)$ & \\
\hline$>5-10$ years & $148(24.1)$ & \\
\hline$>10-15$ years & $105(17.1)$ & \\
\hline$>15$ years & $95(15.5)$ & \\
\hline \multicolumn{3}{|c|}{ Combining psychiatric symptoms $(n=624)$} \\
\hline 0 & $408(65.4)$ & \\
\hline 1 & $168(26.9)$ & \\
\hline$\geq 2$ & $48(7.7)$ & \\
\hline \multicolumn{2}{|l|}{ Y-BOCS scores $(n=638)$} & $19.65(7.61)$ \\
\hline None & $24(3.8)$ & \\
\hline Mild & $145(22.7)$ & \\
\hline Moderate & $303(47.5)$ & \\
\hline Severe & $166(26.0)$ & \\
\hline \multicolumn{3}{|c|}{ Social function status $(\mathrm{n}=629)$} \\
\hline
\end{tabular}

Continued 


\begin{tabular}{lcc}
\hline Table 1 & Continued & \\
\hline Characteristics & N (\%) & Mean (SD) \\
\hline None & $83(13.2)$ & \\
Mild & $149(23.7)$ & \\
Moderate & $287(45.6)$ & \\
Severe & $110(17.5)$ & \\
\hline
\end{tabular}

OCD, obsessive-compulsive disorder; RMB, renminbi; Y-BOCS, Yale Brown Obsessive-Compulsive Scale.

CI: 72.69 to 88.40 ) days, and that for relatives were 26.09 (95\% CI: 21.58 to 30.59) days. Per capita patient labour loss costs were 8542.35 (95\% CI: 7515.71 to 9568.99) RMB (equal to US\$1208.25 (95\% CI: US\$1063.04 to US\$1353.46)), which accounted for $77.56 \%$ of the indirect costs; per capita relatives' labour loss costs were 2349.65 (95\% CI: 1951.08 to 2748.22) RMB (equal to US\$332.34 (95\% CI: US\$275.97 to US\$388.72)), which accounted for $21.33 \%$ of the indirect costs; and other indirect costs accounted for only $1.10 \%$ (see table 3.).

\section{Total estimated cost of OCD}

The annual total cost of OCD per capita was 24503.78 (95\% CI: 22621.53 to 26 386.03) RMB (equal to US\$3465.88 (95\% CI: US\$3199.65 to US\$3732.11)). For families, the annual total costs per capita were 24691.11 (95\% CI: 17728.38 to 31653.85 ) RMB (equal to US\$3492.38 (95\% CI: US\$2507.55 to US\$4477.21)). Weighted by socioeconomic status of place of residence, age and gender, the total cost per capita of OCD was 21826.20 (95\% CI: 20211.64 to 23 440.75) RMB (equal to US\$3087.16 (95\% CI: US\$2858.79 to US\$3315.52)), the direct costs per capita were 13014.46 (95\% CI: 11943.65 to 14085.27 ) RMB (equal to US\$1840.80 (95\% CI: US\$1689.34 to US\$1992.26)), the direct medical costs per capita were 9787.77 (95\% CI: 8969.78 to 10605.75 ) RMB (equal to US\$1384.41 (95\% CI: US\$1268.71 to US\$1500.11)), the indirect cost per capita were 8811.74 (95\% CI: 7914.18 to

\begin{tabular}{lcc}
\hline \multicolumn{3}{l}{ Table 2 The SF-12 scores of patients with OCD $(\mathrm{n}=639)$} \\
\hline Dimension & Mean & SD \\
\hline General health & 43.55 & 26.36 \\
Physical health & 77.59 & 26.01 \\
Role physical & 40.25 & 45.76 \\
Bodily pain & 74.29 & 28.12 \\
Role emotional & 31.21 & 39.44 \\
Mental health & 51.15 & 22.18 \\
Vitality & 45.97 & 23.96 \\
Social functioning & 58.18 & 27.11 \\
Physical Component Summary & 58.92 & 23.04 \\
Mental Component Summary & 46.63 & 22.76 \\
SF-12 score & 52.78 & 20.46 \\
\hline
\end{tabular}

OCD, obsessive-compulsive disorder; SF-12, 12-Item Short-Form Health Survey.
9709.29) RMB (equal to US\$1246.36 (95\% CI: US\$1119.40 to US\$1373.31)). In 2019, China's population was 1.4 billion, $74.47 \%$ of which ( 1.04 billion) were those aged $16-65$ years old. Using the OCD prevalence rate of $1.63 \%^{1}$ and an annual visit rate of $10.2 \%$ (based on a study from Singapore) ${ }^{8}$ we calculated the annual cost of OCD in China to be 37.74 billion (95\% CI: 34.95 billion to 40.53 billion) RMB (equal to US\$5.34 billion (95\% CI: US\$4.94 billion to US\$5.73 billion)). The annual direct costs were 22.50 billion (95\% CI: 20.65 billion to 24.35 billion) RMB (equal to US $\$ 3.18$ billion (95\% CI: US\$2.92 billion to US\$3.44 billion)), the annual direct medical costs were 16.92 billion (95\% CI: 15.51 billion to 18.34 billion) RMB (equal to US\$2.39 billion (95\% CI: US\$2.19 billion to US\$2.59 billion)), and the annual indirect costs were 15.24 billion (95\% CI: 13.68 billion to 16.79 billion) RMB (equal to US\$2.16 billion (95\% CI: US\$1.93 billion to US\$2.37 billion)).

\section{Sensitivity analysis}

The unweighted annual total cost of OCD per capita was 24503.78 (95\% CI: 22621.53 to 26 386.03) RMB (equal to US\$3465.88 (95\% CI: US\$3199.65 to US\$3732.11)). With the same prevalence and annual visit rate, the annual cost of OCD in China reached 42.37 billion (95\% CI: 39.11 billion to 45.62 billion) RMB (equal to US\$5.99 billion (95\% CI: US $\$ 5.53$ billion to US\$6.45 billion)). The total cost of unweighted OCD increased by $12.30 \%$ (95\% CI: $11.90 \%$ to $12.56 \%$ ) compared with the weighted. When the prevalence of OCD is 1\%-3\%, the total cost is 23.15 billion $(95 \%$ CI: 21.44 billion to 24.87 billion) RMB (equal to US\$3.27 billion (95\% CI: US\$3.03 billion to US\$3.52 billion)), with an average reduction of $38.66 \%$, and 69.46 billion (95\% CI: 64.32 billion to 74.60 billion) RMB (equal to US\$9.82 billion (95\% CI: US\$9.10 billion to US\$10.55 billion)), with an average increase of $84.05 \%$. If the treatment rate of OCD increases to $20 \%$, the total cost will increase by $96.08 \%$. If the treatment rate is $50 \%$, the total cost will increase by $390.20 \%$. When the treatment rate reaches $100 \%$, the total cost will increase by $880.39 \%$, which is 370.00 billion RMB (equal to US\$52.33 billion).

\section{Multivariate analysis}

Worse social function status, more psychiatric comorbidity and higher Y-BOCS scores were negatively correlated with the quality of life for patients with OCD (see table 4). The number of clinic and hospitalisation visits, socioeconomic status, education, Y-BOCS scores and age were found to be significantly associated with total cost (see table 5).

\section{DISCUSSION \\ Main findings}

Our findings showed that OCD is a costly disorder associated with a low quality of life in China just as it is in more developed countries. The high national cost of OCD (estimated at US\$5.34 billion (95\% CI: US\$4.94 to US $\$ 5.73$ billion)) indicates that OCD is associated with a large economic burden for China. For the sensitivity analysis based on the prevalence of OCD, the total cost of 


\begin{tabular}{|c|c|c|}
\hline & Patient costs, mean $(95 \% \mathrm{Cl})$ & Family costs, mean $(95 \% \mathrm{Cl})$ \\
\hline Direct costs & 13490.27 (12 324.89 to 14655.65$)$ & 10199.89 (9211.74 to 11188.04$)$ \\
\hline Registration costs & 778.24 (683.22 to 873.26$)$ & \\
\hline Drug costs & 4002.13 (3690.08 to 4314.19$)$ & \\
\hline Inpatient costs & 3393.54 (2723.87 to 4063.21$)$ & \\
\hline Other direct medical costs & 650.07 (405.73 to 894.41$)$ & \\
\hline Direct non-medical costs & 3359.75 (2858.94 to 3860.55$)$ & $3359.75(2858.94$ to 3860.55$)$ \\
\hline Transportation costs & $1897.98(1557.39$ to 2238.57$)$ & \\
\hline Other direct non-medical costs & 146.99 (61.21 to 232.77$)$ & \\
\hline Indirect costs & 11013.51 (9852.41 to 12174.61$)$ & 14268.03 (7905.45 to 20630.60$)$ \\
\hline Patient labour loss days & 80.55 (72.69 to 88.40$)$ & \\
\hline Patient labour loss costs & 8542.35 (7515.71 to 9568.99$)$ & $7131.60(5731.71$ to 8531.49$)$ \\
\hline Relatives' labour loss days & 26.09 (21.58 to 30.59$)$ & \\
\hline Relatives' labour loss costs & 2349.65 (1951.08 to 2748.22$)$ & 7014.72 (790.99 to 13238.46$)$ \\
\hline Other indirect costs for anything OCD related & $121.51(63.83$ to 179.20$)$ & \\
\hline Total costs & 24503.78 (22 621.53 to 26386.03 ) & 24691.11 (17 728.38 to 31653.85$)$ \\
\hline
\end{tabular}

OCD, obsessive-compulsive disorder; RMB, renminbi.

Chinese patients with OCD was between US $\$ 3.27$ billion (95\% CI: US $\$ 3.03$ to US $\$ 3.52$ billion) and US $\$ 9.82$ billion (95\% CI: US $\$ 9.10$ to US $\$ 10.55$ billion). Based on the visit rate of OCD, the total cost of patients with OCD in China could even increase to US\$52.33 billion. Social function status, combining psychiatric symptoms, Y-BOCS scores and age, were influencing factors for the quality of life of patients with OCD. The number of clinic and hospitalisation visits, socioeconomic status, education, Y-BOCS scores and age were found to be the factors significantly associated with the total cost.

Consistent with previous studies, the quality of life of patients with OCD in this study was also significantly impaired. ${ }^{17} 18$ Multiple domains of the quality of life appeared to be affected. In this study, the OCD's emotional role was impaired the most. This indicates that emotional health is impaired more than physical health and may point to the need for more emotional support.
The literature indicates that compared with healthy and community populations, patients with OCD have a lower quality of life. ${ }^{19}{ }^{20}$ Although our study supports this finding, the extent of lower quality of life may be an underestimate as the quality of life was assessed after patients had received treatment. The regression models only explained $41.9 \%$ of the variation in SF-12 scores. This may be because the quality of life of patients with OCD is related to anxiety and depression symptoms ${ }^{2122}$ and/or personality traits that were not assessed in this study.

OCD has not been regarded as a priority for the Chinese healthcare system. Quantifying the total economic cost of OCD can provide an important perspective on the social impact of OCD. Information on the cost of OCD could have a potential impact on China's health policy and healthcare resource allocation decisions. The cost of OCD was 37.74 billion RMB (US\$5.34 billion) and the estimated direct medical cost of OCD was 16.92 billion

Table 4 Linear regression analysis of the quality of life of patients with OCD

\begin{tabular}{llllll}
\hline & $\begin{array}{l}\text { Unstandardised } \\
\text { coefficients (B) }\end{array}$ & SE & $\begin{array}{l}\text { Standardised } \\
\text { coefficients }\end{array}$ & t & P value \\
\hline Social function status & -8.892 & 0.774 & -0.396 & -11.487 & $<0.001$ \\
Combining symptoms & -7.055 & 0.859 & -0.280 & -8.209 & $<0.001$ \\
Y-BOCS scores & -7.887 & 1.041 & -0.241 & -7.576 & $<0.001$ \\
\hline
\end{tabular}

$\mathrm{N}=639$; adjusted $\mathrm{R}^{2}=41.9 \% ; \mathrm{F}=142.973 ; \mathrm{p}<0.001$.

OCD, obsessive-compulsive disorder; SE, Standard error; Y-BOCS, Yale Brown Obsessive-Compulsive Scale. 
Table 5 Generalised linear model of the total costs of patients with OCD

\begin{tabular}{llrc}
\hline & Wald & df & P value \\
\hline Number of inpatient visits & 35.842 & 2 & $<0.001$ \\
\hline Number of outpatient visits & 22.37 & 10 & 0.013 \\
Y-BOCS score & 14.348 & 3 & 0.002 \\
Socioeconomic status & 12.678 & 3 & 0.005 \\
Age & 14.612 & 2 & 0.001 \\
Education & 7.387 & 2 & 0.025 \\
\hline
\end{tabular}

$\mathrm{N}=639$; likelihood ratio $\chi^{2}=114.765 ; \mathrm{p}<0.001$.

df, degrees of freedom; OCD, obsessive-compulsive disorder; YBOCS, Yale Brown Obsessive-Compulsive Scale.

RMB (US\$2.39 billion). The total cost of OCD represents about $0.3 \%$ of total national healthcare costs in China (16.92 billion $\mathrm{RMB} / 6584.14$ billion $\mathrm{RMB}){ }^{23}$ The direct medical costs per capita for OCD is $9787.77 \mathrm{RMB}$, which is more than double the per capita health expenditure in China (4702.79 RMB). ${ }^{24}$ The annual direct cost per OCD sufferer was US\$1840.80 and indirect cost (predominantly lost productivity) was US\$1384.41 in China. This is higher than the per capita direct cost of OCD and lower than the indirect cost of OCD in the USA. ${ }^{25}$ However, these studies from the USA require updating as they were published in 1990, that is, 30 years ago.

Compared with the cost of mental disorder in China, the cost of OCD is lower than that of depression (51.37 billion RMB). The cost of depression in 2002 showed that the direct cost per capita was $8090 \mathrm{RMB}$ and the indirect cost per capita was $43280 \mathrm{RMB} .{ }^{26}$ After adjusting the price index, the direct cost of OCD is not much different from that of depression, but it is much lower than the indirect cost. The cost of OCD is not much different from the cost of schizophrenia, but the direct cost is higher than that of schizophrenia. ${ }^{27}$ The burden of OCD is significant for patients and their families, just as for other mental disorders, hence advocacy is required to ensure that governments and policymakers consider the costs of OCD when allocating health resources.

The direct cost per patient with OCD in this study was $55.05 \%$ of the total costs and this finding is different from the study in the USA, where the indirect burden of OCD was estimated to be higher at $71 \%$ of the total costs. Explanations for this discrepancy may be related to our use of human capital method to estimate the loss of productivity and higher costs of psychiatric medicine in China as psychotropic drugs are imported to China. Data for family household costs have revealed average annual direct medical costs of 6858.68 RMB and average annual indirect costs of 14268.03 RMB. Compared with the social cost of OCD, the direct medical costs have been reduced by an average of $3271.84 \mathrm{RMB}$ and the indirect costs have increased by an average of $3254.52 \mathrm{RMB}$. The reduction in direct medical costs paid by households is owing to a partial reimbursement from the China's insurance mechanism though the reimbursement is limited, merely $32.30 \%$ on average. The increase in indirect costs of families in China is mainly caused by the parents of patients with OCD, who are also the main provider of the households. Since parents of some patients with OCD work longer hours, have more production skills and higher positions, their labour loss days were more costly for the family. The increase in indirect costs of OCD is significant for families of patients with OCD in China because families provide major financial and emotional support.

\section{Limitations}

This study is the first attempt to estimate the economic consequences of OCD in China. The study has a number of limitations. First, our series was not a randomly selected sample. Our sample may not be representative of the whole of China, but our sample was basically similar to some of the epidemiological characteristics of OCD. For example, the psychiatric symptoms of patients with OCD were almost all depression and anxiety, which were $16.4 \%$ and $7.1 \%$, respectively. Depression and anxiety are comorbidities of the normalisation of OCD, and the combined prevalence was similar to the comorbidity of OCD. ${ }^{28} 29$ Second, the costs are estimated from the personal interview data of those who sought treatment. Patients with OCD who rarely attend for treatment or death cases are not included. Finally, owing to the lack of some mental healthcare information about OCD (such as OCD visit rate), uncertainty exists within the estimates of the cost of OCD.

\section{Implications}

OCD is associated with a low quality of life and is a costly disease in China. Government policymakers should seriously consider further investments in mental health services. In addition to the impact of quality of life and income, OCD also impacts significantly on the physical and mental health of the patient and their family members, resulting in less well-measured non-economic impacts. The burden of OCD is significant and more studies are needed to enhance our understanding of this burden.

\section{Author affiliations}

${ }^{1}$ Shanghai Mental Health Center,Shanghai Jiao Tong University School of Medicine, Shanghai, China

${ }^{2}$ The Second Affiliated Hospital of Xinxiang Medical University, Xinxiang, Henan, China

${ }^{3}$ Suzhou Guangji Hospital, Suzhou, Jiangsu Province, China

${ }^{4}$ The First Psychiatric Hospital of Harbin, Harbin, Heilongjiang Province, China ${ }^{5}$ Department of psychiatry, The First Affiliated Hospital of Xi'an Jiaotong University, Xi'an, Shaanxi Province, China

${ }^{6}$ First Affiliated Hospital of Kunming Medical University, Kunming, Yunnan Province, China

${ }^{7}$ Shandong Provincial Hospital, Shandong First Medical University, Jinan, Shandong Province, China

${ }^{8}$ Qingdao Mental Health Center, Qingdao, Shandong Province, China

${ }^{9}$ Affiliated Mental Health Center \& Hangzhou Seventh People's Hospital, Zhejiang University School of Medicine, Hangzhou, Zhejiang Province, China

${ }^{10}$ The Department of Clinical Psychology, Beijing Anding Hospital, Capital Medical University, Beijing, China 
${ }^{11}$ Department of Psychiatry, Qiqihar Medical University, Qiqihar, Heilongjiang Province, China

${ }^{12}$ Guangzhou Brain Hospital Affiliated to Guangzhou Medical University, Guangzhou, Guangdong Province, China

${ }^{13}$ Peking University Sixth Hospital, Peking University Institute of Mental Health, Peking University, Beijing, China

${ }^{14}$ The University of Sydney, Nepean Hospital, Sydney Medical School, Sydney, New South Wales, Australia

Acknowledgements The authors thank all the volunteers who took part in the study.

Contributors ZW contributed to the implementation of the research protocol and has critically revised and approved the final manuscript. WY contributed to statistical analyses and writing the paper. WY, ZT, XW, XM, YC, BW, PS, WT, JL, CW, $\mathrm{PL}, \mathrm{GX}$ and JY participated in data collection. VB interpreted the data and modified the language. ZW was responsible for the overall content as the guarantor.

Funding This research was supported by grants from the Shanghai Municipal Health Commission (SMHC) (2019ZB0201), Shanghai Clinical Research Center for Mental Health (19MC1911100) and SMHC Clinical Research Center (CRC2018ZD03).

Competing interests None declared.

Patient consent for publication Not required.

Provenance and peer review Not commissioned; externally peer reviewed.

Data availability statement Data are available upon reasonable request. The data that support the findings of this study are available from the corresponding author upon reasonable request.

Open access This is an open access article distributed in accordance with the Creative Commons Attribution Non Commercial (CC BY-NC 4.0) license, which permits others to distribute, remix, adapt, build upon this work non-commercially, and license their derivative works on different terms, provided the original work is properly cited, appropriate credit is given, any changes made indicated, and the use is non-commercial. See: http://creativecommons.org/licenses/by-nc/4.0/.

ORCID iDs

Weili Yang http://orcid.org/0000-0002-2281-6073

Zhen Wang http://orcid.org/0000-0003-4319-5314

\section{REFERENCES}

1 Huang $\mathrm{Y}$, Wang $\mathrm{Y}$, Wang $\mathrm{H}$, et al. Prevalence of mental disorders in China: a cross-sectional epidemiological study. Lancet Psychiatry 2019;6:211-24.

2 Heyman I, Mataix-Cols D, Fineberg NA. Obsessive-Compulsive disorder. BMJ 2006;333:424-9.

3 Walitza S, Melfsen S, Jans T, et al. Obsessive-Compulsive disorder in children and adolescents. Deutsches Aerzteblatt Online 2011;108.

4 Murray CJ, Lopez AD. Evidence-based health policy--lessons from the Global Burden of Disease Study. Science 1996;274:740-3.

5 DuPont RL, Rice DP, Shiraki S, et al. Economic costs of obsessivecompulsive disorder. Med Interface 1995;8:102-9.

6 Hollander E. Obsessive-compulsive disorder: the hidden epidemic. $J$ Clin Psychiatry 1997;58 Suppl 12:3-6.

7 Pérez-Vigil A, Mittendorfer-Rutz E, Helgesson M, Ana P-V, Ellenor MR, Magnus $\mathrm{H}$, et al. Labour market marginalisation in obsessive- compulsive disorder: a nationwide register-based sibling control study. Psychol Med 2019;49:1015-24.

8 Subramaniam M, Abdin E, Vaingankar JA, et al. Obsessive-compulsive disorder: prevalence, correlates, help-seeking and quality of life in a multiracial Asian population. Soc Psychiatry Psychiatr Epidemiol 2012;47:2035-43.

9 Hertenstein E, Thiel N, Herbst N, et al. Quality of life changes following inpatient and outpatient treatment in obsessive-compulsive disorder: a study with 12 months follow-up. Ann Gen Psychiatry 2013;12:4.

10 American Psychiatry Association. Diagnostic and statistical manual of mental disorders, 5th edition: DSM-5. 5th edn. Washington, DC: American Psychiatric Publishing, 2013.

11 Kadiyala PK. Mnemonics for diagnostic criteria of DSM V mental disorders: a scoping review. General Psychiatry 2020;33:e100109.

12 Goodman WK, Price LH, Rasmussen SA, et al. The Yale-Brown obsessive compulsive scale. I. development, use, and reliability. Arch Gen Psychiatry 1989;46:1006-11.

13 Je W, Kosinski M, Keller SD. A 12-Item short-form health survey. Med Care 1996;34:220-33.

14 Meng Y, Zhang X, Han J. The impact of medical insurance programmes on the health of the insured: evidence from China. Int $J$ Health Plann Manage 2020;35:718-34.

15 Bhattarai G. Understanding the outliers in healthcare expenditure data. Paper presented at the 26th NorthEast SAS User Group Annual Meeting, 2013.

16 Griswold M, Parmigiani G, Potosky A, et al. Analyzing health care costs: a comparison of statistical methods motivated by Medicare colorectal cancer charges. Biostatistics 2004;1:1-23.

17 Eisen JL, Mancebo MA, Pinto A, et al. Impact of obsessivecompulsive disorder on quality of life. Compr Psychiatry 2006;47:270-5

18 Hou S-Y, Yen C-F, Huang M-F, et al. Quality of life and its correlates in patients with obsessive-compulsive disorder. Kaohsiung J Med Sci 2010;26:397-407.

19 Bobes J, González MP, Bascarán MT, et al. Quality of life and disability in patients with obsessive-compulsive disorder. Eur Psychiatry 2001;16:239-45.

20 Remmerswaal KCP, Batelaan NM, Hoogendoorn AW, et al. Four-Year course of quality of life and obsessive-compulsive disorder. Soc Psychiatry Psychiatr Epidemiol 2020;55:989-1000.

21 Jahangard L, Fadaei V, Sajadi A, et al. Patients with OCD report lower quality of life after controlling for expert-rated symptoms of depression and anxiety. Psychiatry Res 2018;260:318-23.

22 Masellis M, Rector NA, Richter MA. Quality of life in OCD: differential impact of obsessions, compulsions, and depression comorbidity. Can J Psychiatry 2003;48:72-7.

23 National Bureau of Statistics. Total health expenditure in China, 2019. Available: https://data.stats.gov.cn/easyquery.htm?cn=A01

24 National Bureau of Statistics. Per capita health expenditure in China, 2019. Available: https://data.stats.gov.cn/easyquery.htm?cn=C01

25 Maj M, Sartorius N, Okasha A, et al. Obsessive-compulsive disorder. 2 edn. New Jersey: John Wiley \& Sons Ltd, 2002.

26 Hu T-wei, He Y, Zhang M, et al. Economic costs of depression in China. Soc Psychiatry Psychiatr Epidemiol 2007;42:110-6.

27 Zhai J, Guo X, Chen M, et al. An investigation of economic costs of schizophrenia in two areas of China. Int J Ment Health Syst 2013;7.

28 Bhattacharyya S, Reddy YCJ, Khanna S. Depressive and anxiety disorder comorbidity in obsessive compulsive disorder. Psychopathology 2005;38:315-9.

29 Lochner C, Fineberg NA, Zohar J, et al. Comorbidity in obsessivecompulsive disorder (OCD): a report from the International College of Obsessive-Compulsive spectrum disorders (ICOCS). Compr Psychiatry 2014;55:1513-9.

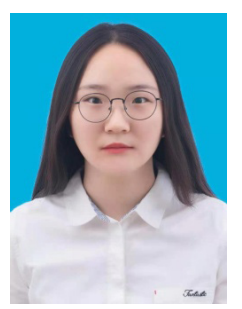

Weili Yang obtained a master's degree in medicine on epidemiology and health statistics from the Shandong First Medical University in China in 2020 and joined the Second Affiliated Hospital of Xinxiang Medical College (Henan mental health center) in September 2020. Her research interest includes health service research of diseases. 